Article

\title{
Compact and Highly Sensitive Bended Microwave Liquid Sensor Based on a Metamaterial Complementary Split-Ring Resonator
}

Said Mosbah ${ }^{1}$, Chemseddine Zebiri ${ }^{1}$ D, Djamel Sayad ${ }^{2}$, Issa Elfergani ${ }^{3,4, * \mathbb{D}}$, Mohamed Lamine Bouknia ${ }^{1}$, Samira Mekki ${ }^{1}$, Rami Zegadi ${ }^{1}\left(\mathbb{D}\right.$, Merih Palandoken ${ }^{5}{ }^{(D}$, Jonathan Rodriguez ${ }^{3}$ and Raed A. Abd-Alhameed ${ }^{4}(\mathbb{D}$

Citation: Mosbah, S.; Zebiri, C.;

Sayad, D.; Elfergani, I.; Bouknia, M.L.;

Mekki, S.; Zegadi, R.; Palandoken, M.;

Rodriguez, J.; Abd-Alhameed, R.A.

Compact and Highly Sensitive

Bended Microwave Liquid Sensor

Based on a Metamaterial

Complementary Split-Ring Resonator.

Appl. Sci. 2022, 12, 2144. https://

doi.org/10.3390/app12042144

Academic Editors: Alessandro Lo

Schiavo and Mario Lucido

Received: 25 December 2021

Accepted: 16 February 2022

Published: 18 February 2022

Publisher's Note: MDPI stays neutral with regard to jurisdictional claims in published maps and institutional affiliations.

Copyright: (C) 2022 by the authors. Licensee MDPI, Basel, Switzerland. This article is an open access article distributed under the terms and conditions of the Creative Commons Attribution (CC BY) license (https:// creativecommons.org/licenses/by/ $4.0 /)$.
1 Laboratoire d'Electronique de Puissance et Commande Industrielle (LEPCI), Department of Electronics, University of Ferhat Abbas, Sétif -1-, Sétif 19000, Algeria; said.mosbah@univ-setif.dz (S.M.); czebiri@univ-setif.dz (C.Z.); ml.bouknia@univ-setif.dz (M.L.B.); samira.mekki@univ-setif.dz (S.M.); ramizegadi@univ-setif.dz (R.Z.)

2 Laboratoire d'Electrotechnique de Skikda (LES), Department of Electrical Engineering, University 20 Aout 1955-Skikda, Skikda 21000, Algeria; d.sayad@univ-skikda.dz

3 Instituto de Telecomunicações, Campus Universitário de Santiago, 3810-193 Aveiro, Portugal; jonthan@av.it.pt

4 Faculty of Engineering and Informatics, University of Bradford, Bradford BD7 1DP, UK; r.a.a.abd@bradford.ac.uk

5 Department of Electrical and Electronics Engineering, Izmir Katip Celebi University, No:33/2, Izmir 35620, Turkey; merih.palandoken@ikcu.edu.tr

* Correspondence: i.t.e.elfergani@av.it.pt or i.elfergani@bradford.ac.uk; Tel.: +35-12-3437-7900

\begin{abstract}
In this paper, we present the design of a compact and highly sensitive microwave sensor based on a metamaterial complementary split-ring resonator (CSRR), for liquid characterization at microwave frequencies. The design consists of a two-port microstrip-fed rectangular patch resonating structure printed on a $20 \times 28 \mathrm{~mm}^{2}$ Roger RO3035 substrate with a thickness of $0.75 \mathrm{~mm}$, a relative permittivity of 3.5, and a loss tangent of 0.0015. A CSRR is etched on the ground plane for the purpose of sensor miniaturization. The investigated liquid sample is put in a capillary glass tube lying parallel to the surface of the sensor. The parallel placement of the liquid test tube makes the design twice as efficient as a normal one in terms of sensitivity and $Q$ factor. By bending the proposed structure, further enhancements of the sensor design can be obtained. These changes result in a shift in the resonant frequency and $Q$ factor of the sensor. Hence, we could improve the sensitivity 10-fold compared to the flat structure. Subsequently, two configurations of sensors were designed and tested using CST simulation software, validated using HFSS simulation software, and compared to structures available in the literature, obtaining good agreement. A prototype of the flat configuration was fabricated and experimentally tested. Simulation results were found to be in good agreement with the experiments. The proposed devices exhibit the advantage of exploring multiple rapid and easy measurements using different test tubes, making the measurement faster, easier, and more cost-effective; therefore, the proposed high-sensitivity sensors are ideal candidates for various sensing applications.
\end{abstract}

Keywords: microwave sensors; complementary split-ring resonator; bended; highly sensitive; resonant frequency; $\mathrm{Q}$ factor

\section{Introduction}

Wireless sensor networks are essential in our society, and are becoming an integral part of our environment [1-6]. These sensors are the object of very active research because of the growing interest in them in many areas, such as environmental monitoring [1,2], industrial control [3], information security [4], the Internet of vehicles [5] and network lifetime [6]. The goal of these studies is to develop sensitive, fast, and easy-to-use sensors. Microwave sensor technology may provide wireless passive sensors in addition to wireless 
sensor networks. Microwave sensors are the current technological framework that has most attracted the attention of researchers in recent years. These sensors offer many advantages, including low manufacturing costs, high sensitivity, and high durability; these advantages make them very attractive and preferred choices in a variety of research fields, including biomedicine [7-10], chemistry [11-13], electronics, and industry [7,14,15]; they have even recently been used in food safety applications and mechanical systems [16-18].

In the field of microwave sensor technology, a new perspective has been developed using the concept of metamaterials $[19,20]$. These are engineered materials first invented by Veselago [21], composed of subwavelength resonators, and have been experimentally validated in recent years. Metamaterials are of great interest, as they effectively contribute to the design of many new devices, ensuring unusual electromagnetic properties that may not be readily available in nature [22,23], such as the realization of passive double-negative metamaterials (DNMs) for simultaneously negative permittivity $(\varepsilon)$ and permeability $(\mu)$, and single-negative metamaterials (SNMs), where either $(\varepsilon)$ or $(\mu)$ is negative, referred to as ENGs and MNGs, respectively [24-27].

In the earlier literature, a variety of split-ring resonator (SRR) [28-31] and complementary split-ring resonator (CSRR) [32-35] sensors have been proposed and studied. SRRs and CSRRs are popular in the design of microwave components, meeting the highest standards of accuracy and sensitivity [36], and show great miniaturization capabilities as they allow a shift of the resonant frequency to lower values [28,37,38]. The disadvantage of SRR-based sensors is that they do not support high electric fields and are not suitable for the detection of large microwave signals. Efforts are constantly deployed to improve microwave sensor systems and overcome this problem. The CSRR-based microwave sensors are based on the electric coupling of CSRRs, which are generally etched in the ground plane and have large electric fields [39], and are the most widely used topology of metamaterials in the design of highly sensitive liquid concentration sensors, due to their low profile and adaptability for various practical applications [40].

In this simulation work, a symmetrical CSRR-based compact and highly sensitive bended microstrip sensor for liquid characterization is presented. This study is based on the flat sensor model studied by Chuma in [41], where the capillary tube placement was arranged to be normal to the surface of the sensor, crossing the patch, the substrate, and the ground plane. Modifications were made to the latter in order to improve its performance. First, the liquid test tube placement was readjusted to lie down on the sensor surface, helping to increase the interaction between the electric field and the examined liquid; this improved both the sensor sensitivity and the $Q$ factor. Second, the flat thin structure was folded around a cylinder of radius $\mathrm{R}$ in order to further increase the contact area between the test tube and the sensor surface.

The resulting bended shape strengthens the slow wave propagation within the structure. Thus, the slow wave effect leads to increased interaction time between the electric field and the liquid under test [27]. This phenomenon allows for higher sensitivity. A simulation study was carried out to characterize diverse mixtures of ethanol and water dielectric liquids with different ethanol concentrations. In practice-for example, in engine fuels, pharmaceuticals, and medicinal formulations [41] — ethanol liquids are generally characterized by their high concentration and versatility. The ethanol samples are placed in a glass tube on the surface of the sensor for sensor safety, the possibility of reuse, and ease of operability. This allows rapid analysis of the liquid's dielectric properties at microwave frequencies.

\section{Sensor Structure and Design Steps}

The basic flat sensor structure [41], consisting of a two-port microstrip-fed rectangular patch, was printed on a $0.75 \mathrm{~mm}$ thick Roger RO3035 substrate with a dielectric constant $\varepsilon_{r}=3.5$ and a loss tangent of $\tan \delta=0.0015$. The structure had overall dimensions of $\mathrm{L} \times \mathrm{W}=20 \times 28 \mathrm{~mm}^{2}$ (Figure 1). The ground copper layer held a complementary split-ring resonator (CSRR). The conductors used in this design (patch and ground plane) consisted 
of $35 \mu \mathrm{m}$ thick copper layers. The final bended sensor configuration is presented in Figure 2. The novelty of this work lies in the investigation of a new bended-shape structure aiming at enhancing the performance of the microwave sensor. The geometric properties of our proposed sensor are given in Table 1.

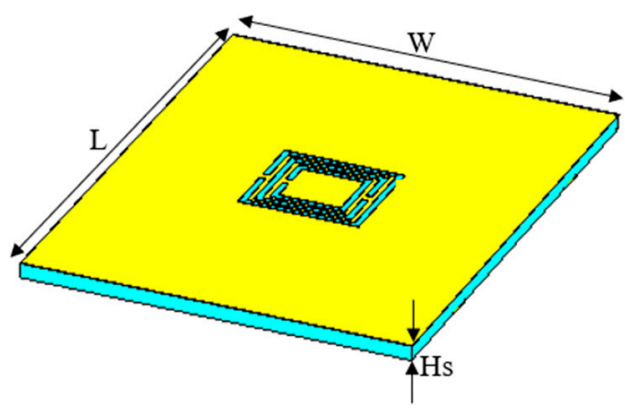

(a)

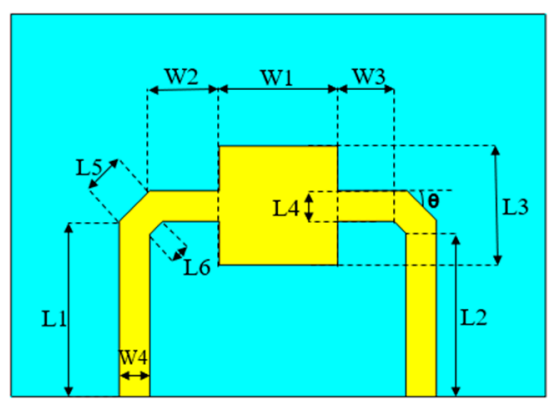

(b)

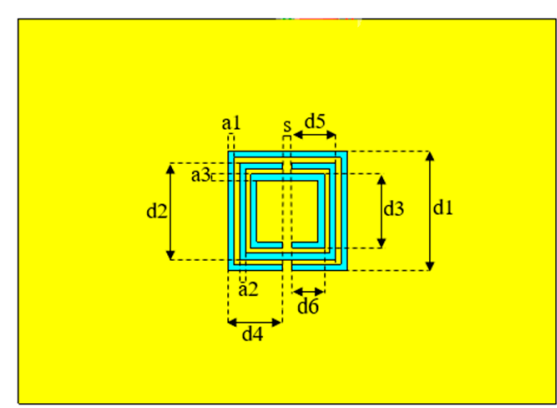

(c)

Figure 1. Geometric dimensions of the flat sensor structure [41]: (a) side view; (b) top view; (c) bottom view.

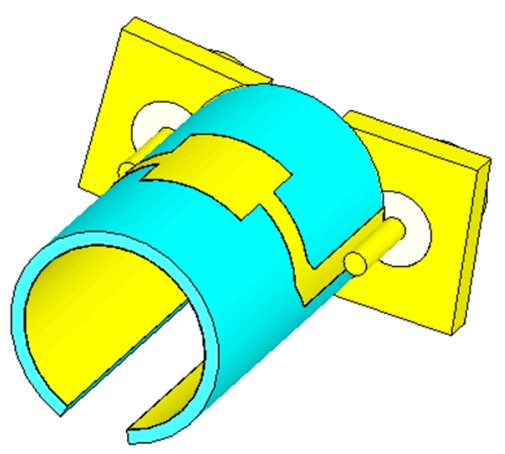

(a)

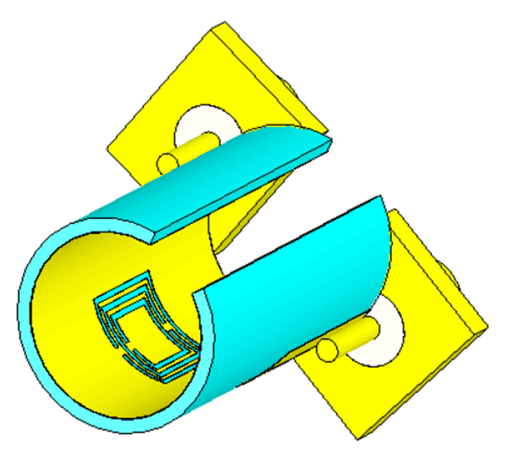

(b)

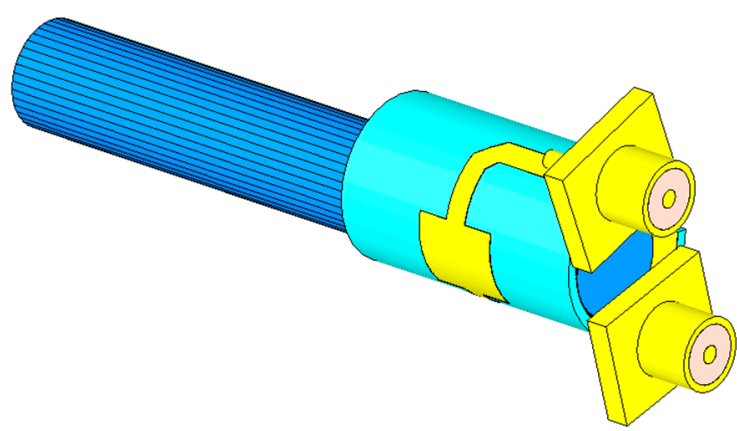

(c)

Figure 2. 3D view of the proposed sensor: (a) upper side view; (b) inner side view; (c) final structure with embedded glass tube.

Table 1. Geometrical parameters of the proposed sensor structure.

\begin{tabular}{lcccccccccccc}
\hline Parameters & W & L & Hs & W1 & W2 & W3 & W4 & L1 & L2 & L3 & L4 & L5 \\
Value $(\mathrm{mm})$ & $\mathbf{2}$ & 20 & 0.75 & 6.2 & 3.6 & 2.94 & 1.6 & 9.2 & 8.54 & 6.2 & 1.6 & 2.26 \\
\hline Parameters & $\mathbf{L 6}$ & $\mathbf{d 1}$ & $\mathbf{d 2}$ & $\mathbf{d 3}$ & $\mathbf{d 4}$ & $\mathbf{d 5}$ & $\mathbf{d 6}$ & $\mathbf{a 1}$ & $\mathbf{a 2}$ & $\mathbf{a 3}$ & $\mathbf{s}$ & $\boldsymbol{\theta}$ \\
Value $(\mathrm{mm})$ & 0.94 & 6.2 & 5.02 & 3.84 & 2.85 & 2.26 & 1.67 & 0.33 & 0.33 & 0.33 & 0.5 & $45^{\circ}$ \\
\hline
\end{tabular}

The sensitivity of the sensor was analyzed according to the $S_{21}$ presented results. The shift in the resonant frequency $\left(\Delta \mathrm{fr}=\mathrm{fr} \_0 \%-\mathrm{fr} \_100 \%\right)$ of $\mathrm{S}_{21}$ was deduced. The percentage of relative frequency shift or $\mathrm{Q}$ factor $\left(\Delta \mathrm{fr}(3 \mathrm{~dB}) / \mathrm{fr} \_\right.$ref $\left.(\%)\right)$ was also considered. Next, the sensitivity of the sensors was defined as the ratio of the resonant frequency change to the permittivity change $\left(\mathrm{S}=\Delta \mathrm{fr} / \Delta \varepsilon \mathrm{r}=\left|\left(\mathrm{fr} \_0 \%-\mathrm{fr} \_100 \%\right)\right| /\left|\left(\varepsilon \mathrm{r} \_0 \%-\varepsilon \mathrm{r} \_100 \%\right)\right|\right)[42,43]$.

The $\mathbf{S}_{\mathbf{2 1}}$ parameter and $\mathrm{Q}$ factor of the proposed bended sensor, along with CST simulation results of mixing with different water-ethanol concentrations, are presented in Figure $3 a, b$, respectively. The final designed sensor exhibited a very high sensitivity and an acceptable quality factor compared to those reported in [41]. The frequency range was $400 \mathrm{MHz}$ for a permittivity range of 65 [44] (see Appendix A). This enabled us to achieve 
a very high sensitivity of 6.15 . Moreover, the sensor operates at a central frequency of $1.8 \mathrm{GHz}$.

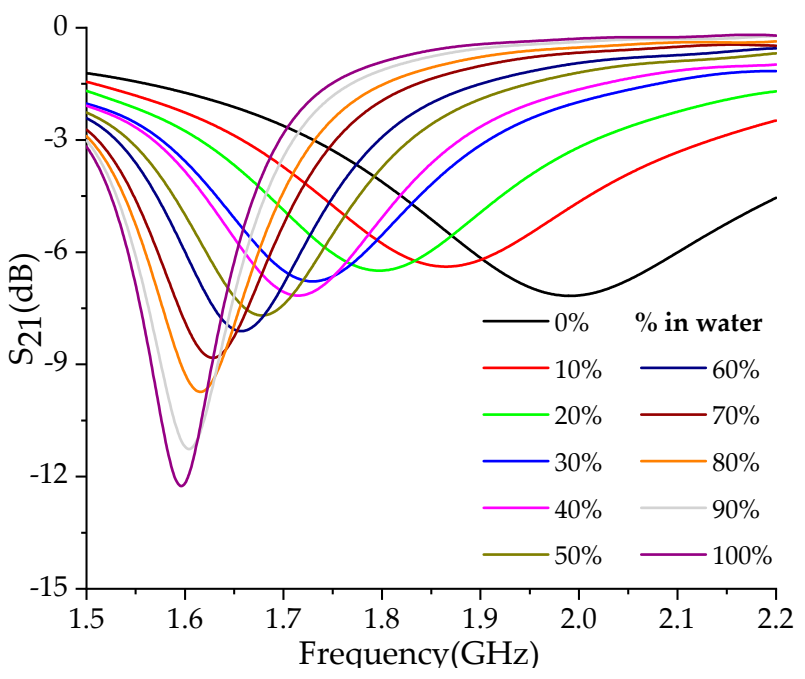

(a)

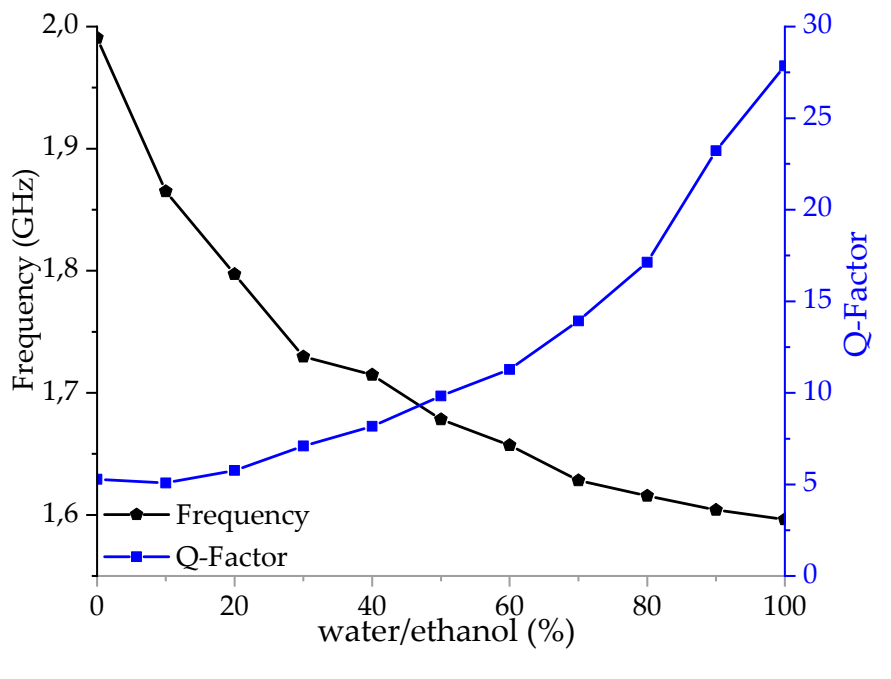

(b)

Figure 3. CST simulations of the flat sensor: (a) $\mathbf{S}_{\mathbf{2 1}}$ parameter and (b) $\mathrm{Q}$ factor of mixtures with different water-ethanol concentrations for the proposed sensor, with test glass radius $\mathrm{r}=3.75 \mathrm{~mm}$.

\section{Simulation, Results, and Discussion}

In the following subsections, we present the stepwise evolution of the proposed design, starting from the validation of Chuma's basic prototype [41], and ending with the final design with the applied modifications- the parallel test tube placement and the bent shape of the sensing structure folded around a cylinder of radius $\mathrm{R}$.

\subsection{Flat Structure}

Figure $4 \mathrm{a}$ illustrates the symmetrical two-port rectangular microstrip-fed patch metamaterial-based flat microwave sensor presented in [41]. A CSRR cell is etched on the ground plane, with a centered hole crossing the patch and substrate, so as to place the test tube of liquid samples normally relative to the surface of the sensor. First, we validated the first basic sensor structure (Figure 4a) by comparing CST simulation results with experiments published in [41], where only experimental results were reported, without simulation validation. The second structure, where the test tube placement was changed to be parallel to the lower side of the sensor from the CSRR side (Figure $4 b$ ), was fabricated as illustrated in Figure 5. The simulations showed good agreement with the experiments (Figure 6).

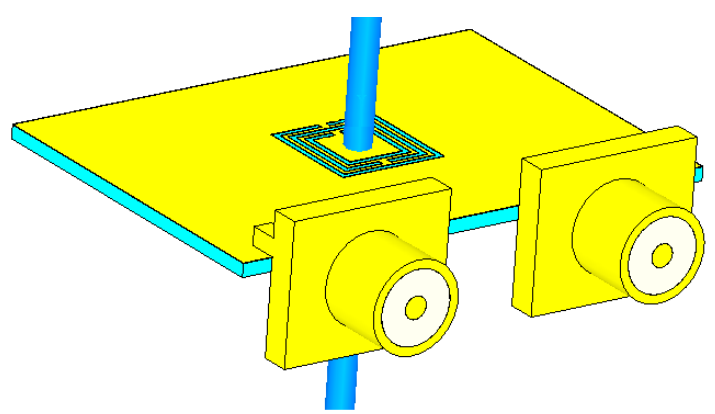

(a)

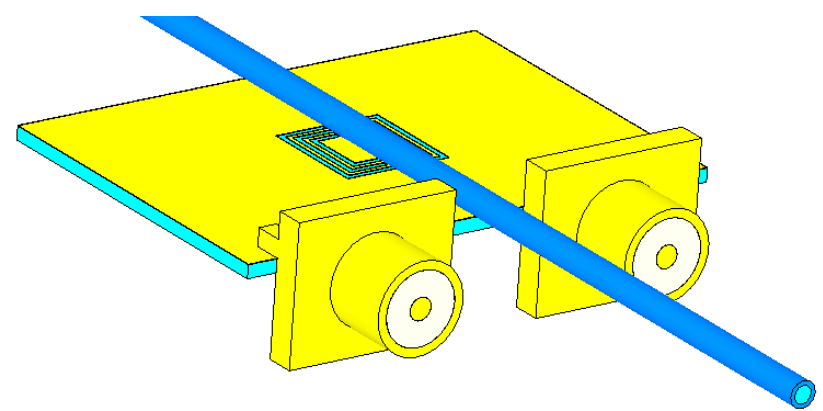

(b)

Figure 4. (a) Sensor structure with a normal glass tube [41]; (b) flat sensor with a parallel glass tube. 
The glass capillary tube was easily produced using a Creality Ender-3 Pro 3D printer using a $0.2 \mathrm{~mm}$ nozzle and PLA filament. This was used in the case of the flat structure measurements. This kind of capillary tube is commonly used in clinical and laboratory settings; it is $75 \mathrm{~mm}$ long, with an outer radius of $0.75 \mathrm{~mm}$, an inner radius of $0.5 \mathrm{~mm}$, and relative permittivity of 5.5. After the confirmation of the microwave sensing application's potential through the numerical computations, the microwave sensor model was fabricated on 0.75 mm thick Roger RO3035 substrate with Eleven Lab PCB prototyping system, as shown in Figure 5.

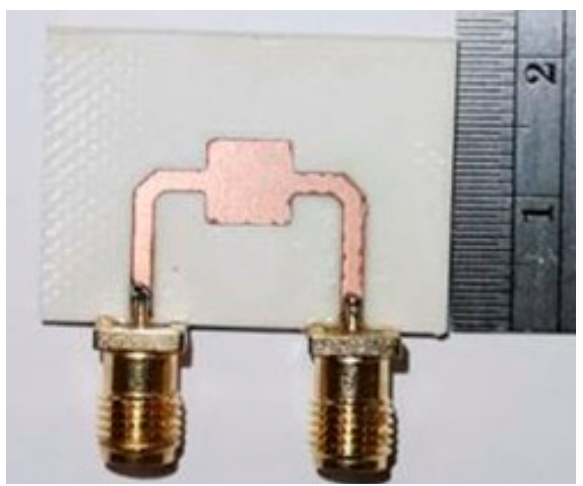

(a)

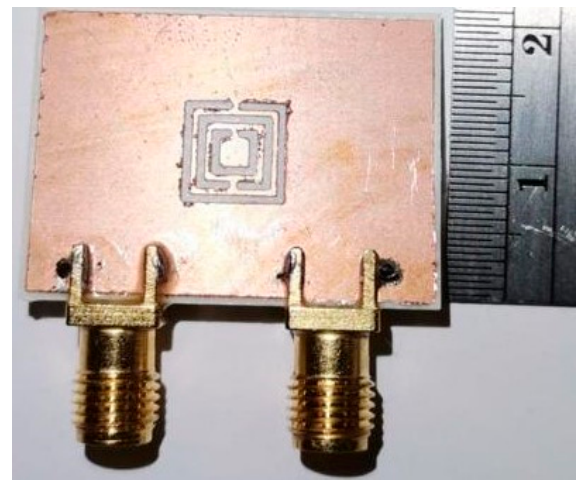

(b)

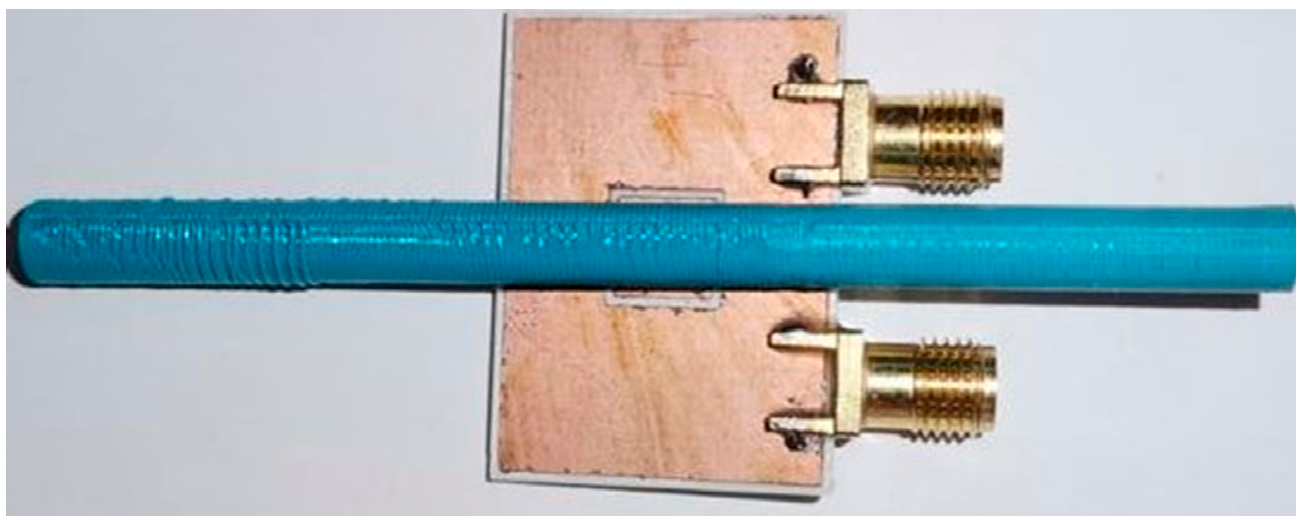

(c)

Figure 5. Fabricated sensor prototype: (a) top view; (b) bottom view; (c) flat sensor with embedded tube.

This new tube placement brought a significant benefit in terms of field interaction with the liquid being tested, significantly enhancing the sensor sensitivity.

Figure 6a illustrates the simulated $S_{21}$ parameter compared to the experimental data reported in [41]. Validation tests on the design show that the simulation results and measurement data are in good agreement for the three considered cases (water concentration $0 \%, 100 \%$, and air (Figures $6 \mathrm{a}$ and $7 \mathrm{~b}$ )). It should be noted that the higher the concentration of water in the mixture, the lower the frequency of the peak. On the other hand, the resonant frequency and quality factor patterns are nearly overlapping, with a shift of less than $5 \mathrm{MHz}$. Figures $6 \mathrm{~b}$ and $7 \mathrm{~b}$ illustrate the parallel glass tube design simulations of water-ethanol mixture, with an outer radius of $r=0.75 \mathrm{~mm}$. As a result, the sensitivity and quality factor values are doubled compared to the normal test tube case. Note that the normal test tube sensor sensitivity factor was $38 \mathrm{MHz}$ [41], while it was $89 \mathrm{MHz}$ for the parallel case, and the quality factors were $47 \%$ and $73 \%$, respectively (Figures $6 \mathrm{~b}$ and $7 \mathrm{~b}$ ). 


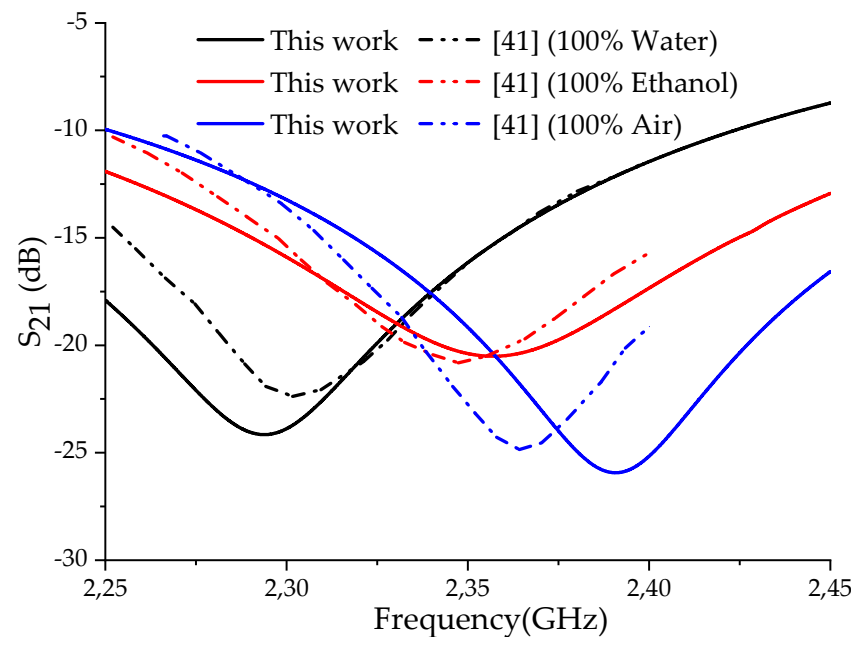

(a)

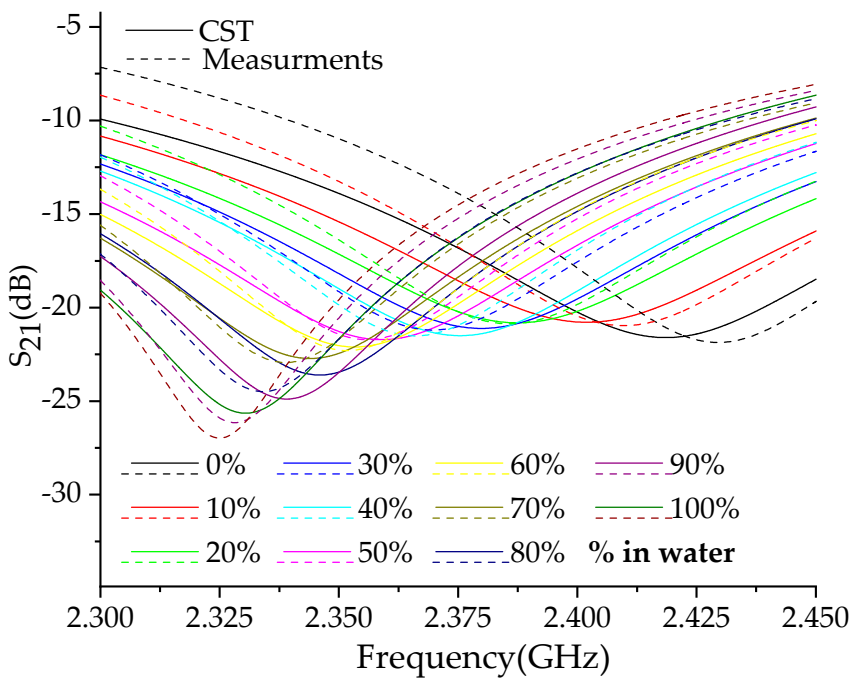

(b)

Figure 6. $S_{21}$ parameter simulations of (a) water, ethanol, and air samples of normal glass tube design compared to measurements [41]; (b) water-ethanol concentration of the designed parallel test tube compared to measurements.

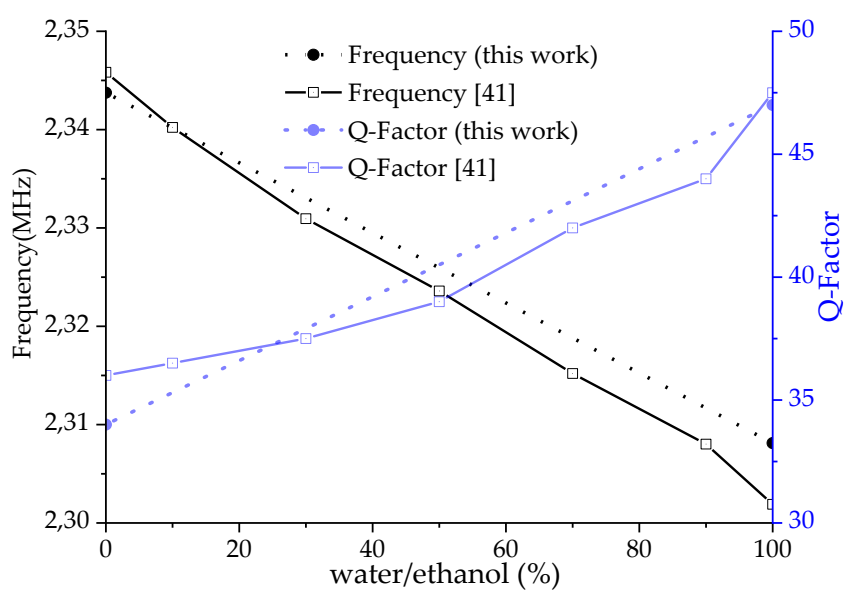

(a)

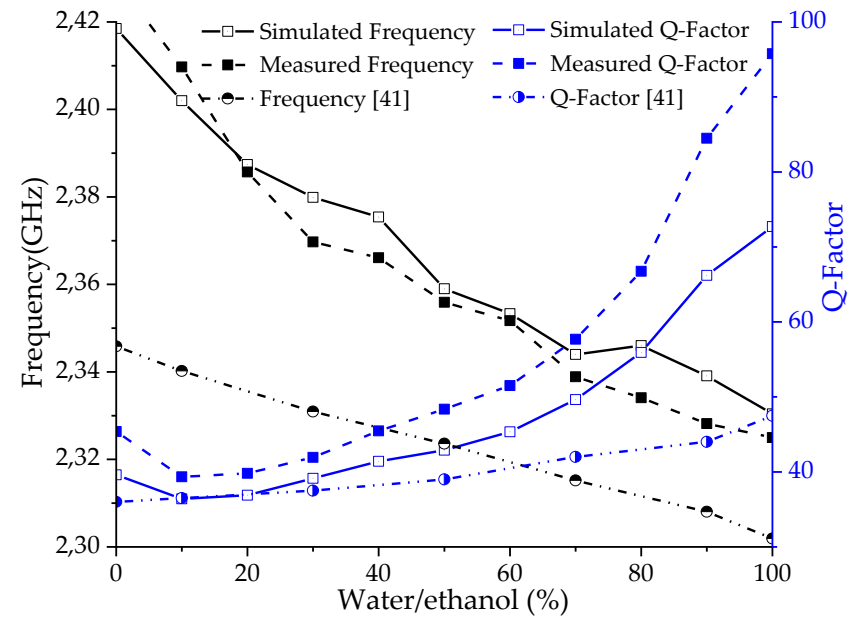

(b)

Figure 7. $\mathrm{Q}$ factor and resonant frequency versus water-ethanol concentration of (a) normal glass tube design compared to measurements [41], and (b) the designed parallel test tube compared to measurements.

\subsection{Bended Structure}

\subsubsection{Effect of the Cylinder's Radius}

In an effort to obtain the highest possible sensitivity factor, various modifications were made to the original configuration. The flat structure was bent into a cylindrical form, and the original size remained unchanged (Figure 8a). Simulations were performed for different values of the cylinder radius $R$. The results for a test tube of radius $R=3.75 \mathrm{~mm}$ are presented in Figure $8 \mathrm{~b}$. The response $S_{21}$ was affected by the bended form of the sensing structure. The frequency band increased proportionally with smaller bending radii. It can be seen that the frequency interval between the upper (100\% water) and lower $(0 \%$ water $)$ water concentrations increases with the decrease in the bending radius for $10 \mathrm{~mm}, 7 \mathrm{~mm}$, and the minimum possible value of $5 \mathrm{~mm}$. Beyond that, the structure is no longer practically 
feasible, due to structure deformation; consequently, the sensitivity increases, and reaches its maximum.

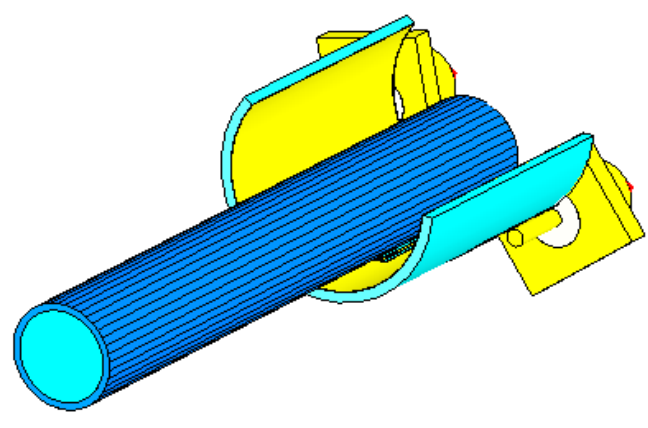

(a)

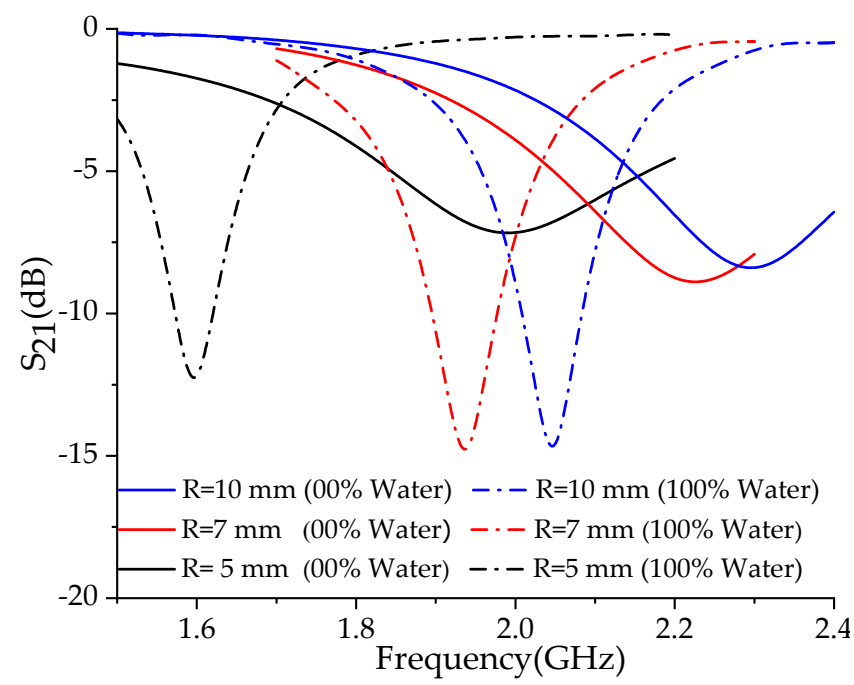

(b)

Figure 8. Designed sensor in the CST interface: (a) bended structure; (b) $\mathbf{S}_{\mathbf{2 1}}$ response of waterethanol mixtures for different bending radii and concentrations.

Bending the structure on a smaller cylinder radius improves and increases the sensor's sensitivity. Table 2 summarizes the main obtained results.

Table 2. Effect of bending radius on the sensitivity $Q$ factor of the bent sensor.

\begin{tabular}{ccccc}
\hline Bending Radius & $\begin{array}{c}\text { Resonant Frequency } \\
\mathbf{0 \%}(\mathbf{M H z})\end{array}$ & $\begin{array}{c}\text { Resonant Frequency } \\
\mathbf{1 0 0 \%} \mathbf{( M H z )}\end{array}$ & $\begin{array}{c}\Delta \text { fr } \\
\mathbf{( M H z )}\end{array}$ & Maximum Q Factor \\
\hline $\mathrm{R}=10 \mathrm{~mm}$ & 2295.6 & 2046.3 & 249.3 & 38.6 \\
$\mathrm{R}=7.5 \mathrm{~mm}$ & 2225.6 & 1936.4 & 289.2 & 34 \\
$\mathrm{R}=5 \mathrm{~mm}$ & 1990.7 & 1596.3 & 394.5 & 27.9 \\
\hline
\end{tabular}

\subsubsection{Effect of the Test Tube Radius}

In addition to its quick and easy handling, the test tube's parallel position configuration enabled us to investigate more possible structure cases according to the tube radius, for optimization purposes. However, the normal configuration [41] allowed only a single radius case $(\mathrm{r}=0.75 \mathrm{~mm})$, since the tube was inserted through a hole drilled in the substrate.

Figure 9 presents a CST simulation validated by Ansys HFSS for a test tube of radius $\mathrm{r}=0.75 \mathrm{~mm}$. The two software $\mathrm{S}_{21}$ response results at resonance were similar for different concentrations, with a $50 \mathrm{MHz}$ offset (Figure $9 \mathrm{a}, \mathrm{b}$ ). A sensor sensitivity of $1.7 \mathrm{kHz}$ and a quality factor of $88.35 \%$ were achieved using CST. These results were close to those obtained at HFSS $1.5 \mathrm{kHz}$ and $62.25 \%$, respectively. For this case, the device operates at around $2.4 \mathrm{GHz}$. 


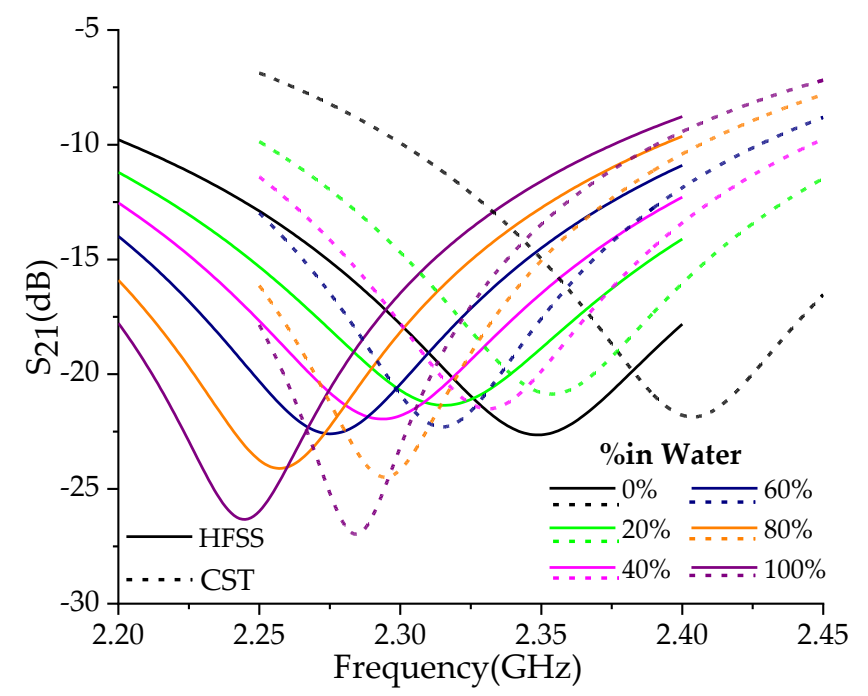

(a)

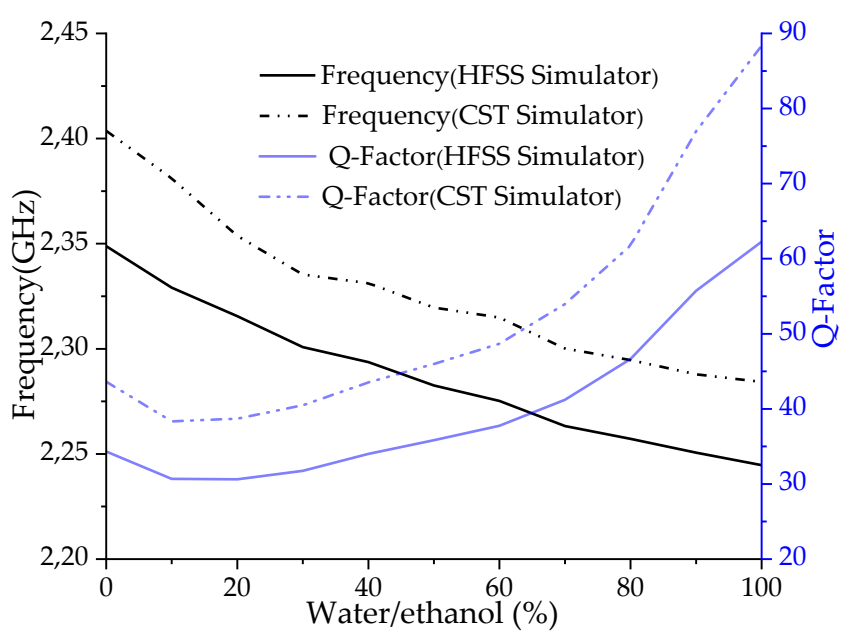

(b)

Figure 9. Simulated results: (a) $S_{21}$ response and (b) resonant frequency and $Q$ factor for different mixture water concentrations, with $\mathrm{r}=0.75 \mathrm{~mm}$.

Similarly, as shown in Figure 10, the sensitivity increased almost 2.5-fold compared to the case with $\mathrm{r}=0.75 \mathrm{~mm}$, while the quality factor (which has a direct link with the imaginary component of the permittivity) decreased by $15 \%$. The CST and HFSS results curves almost overlap. The resonant frequency of this case decreased, averaging $2.2 \mathrm{GHz}$.

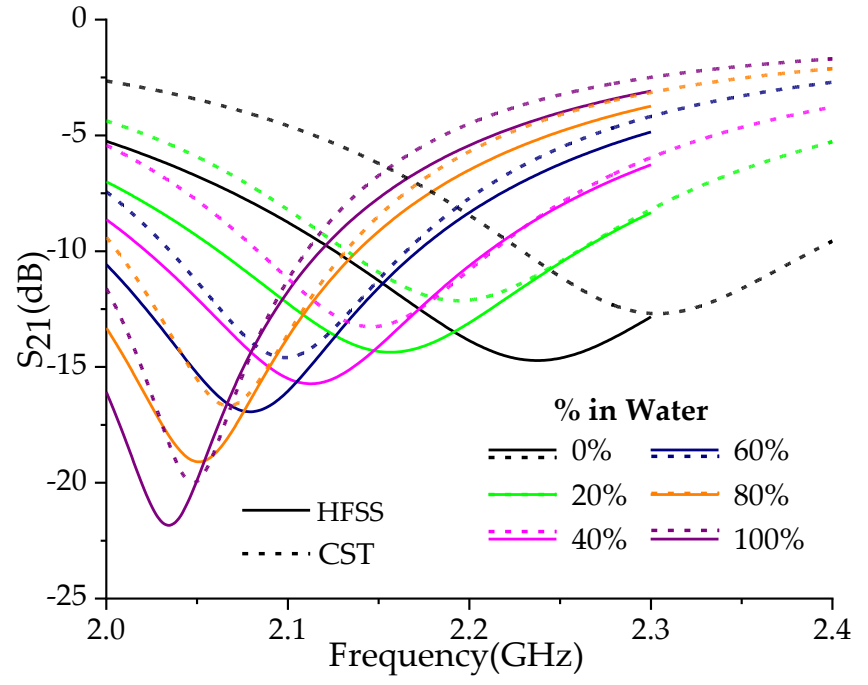

(a)

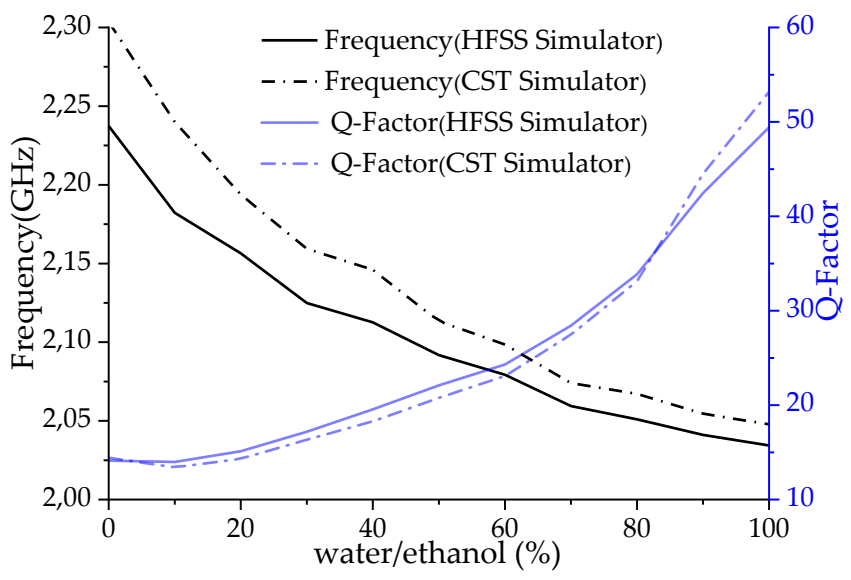

(b)

Figure 10. Simulated results: (a) $S_{21}$ response and (b) resonant frequency and $Q$ factor for different mixture water concentrations, with $\mathrm{r}=1.5 \mathrm{~mm}$.

For $\mathrm{r}=2.5 \mathrm{~mm}$, an improvement in the performance of the proposed sensor was noticed. The frequency band decreased and reached an average value of $2 \mathrm{GHz}$ at resonance, with stable sensitivity and a slight decrease in the quality factor. In addition, the CST- and HFSS-simulated $S_{21}$ results are quite close-almost superimposed (Figure 11). 


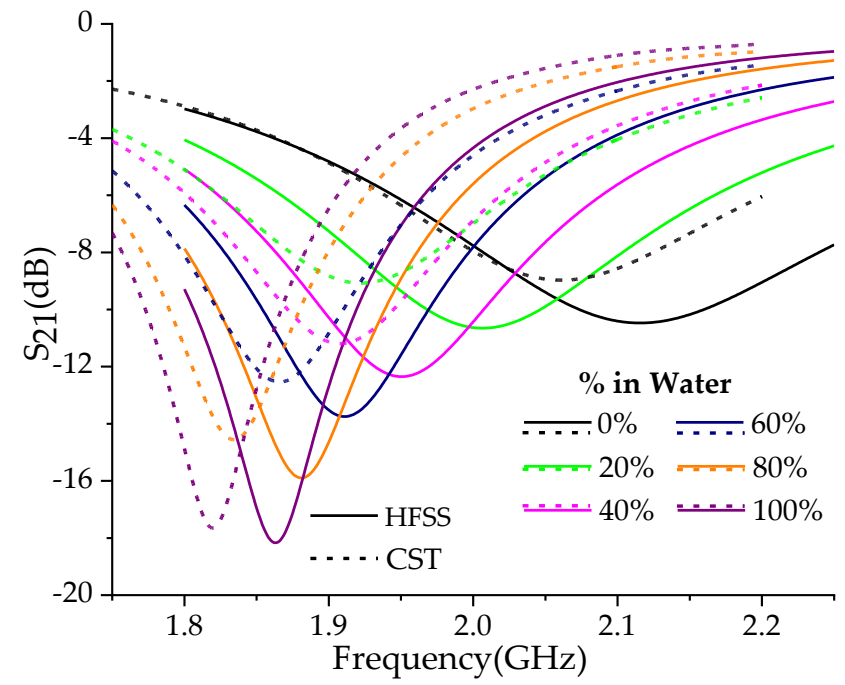

(a)

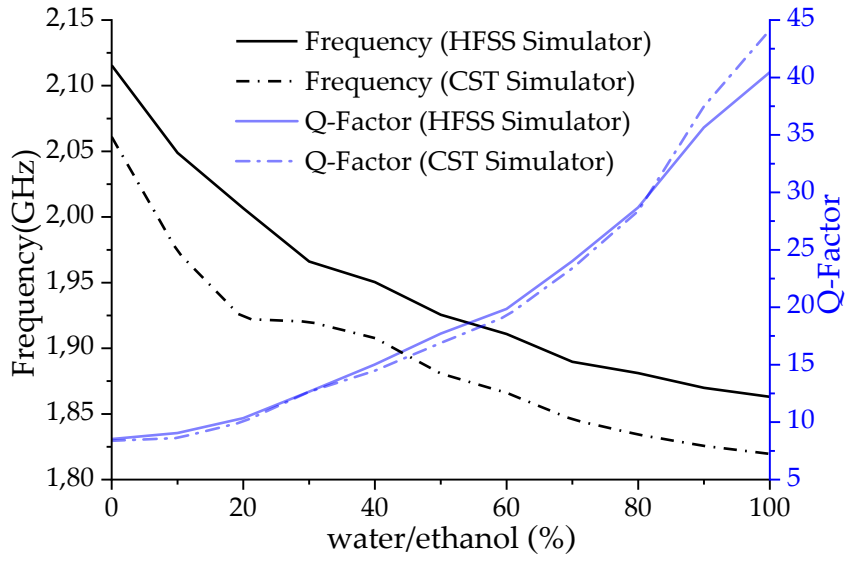

(b)

Figure 11. Simulated results: (a) $S_{21}$ response and (b) resonant frequency and $Q$ factor for different mixture water concentrations, with $\mathrm{r}=2.5 \mathrm{~mm}$.

For $\mathrm{r}=3.75 \mathrm{~mm}$ (Figure 12), the simulation results were closer, and almost overlapped at lower concentrations. On the other hand, they moved slightly further apart at other concentrations, and a remarkable increase in sensitivity compared to the previous cases was observed. In the same way, a slight decrease in the quality factor was observed. The resonant frequency decreased until it reached $1.8 \mathrm{GHz}$.

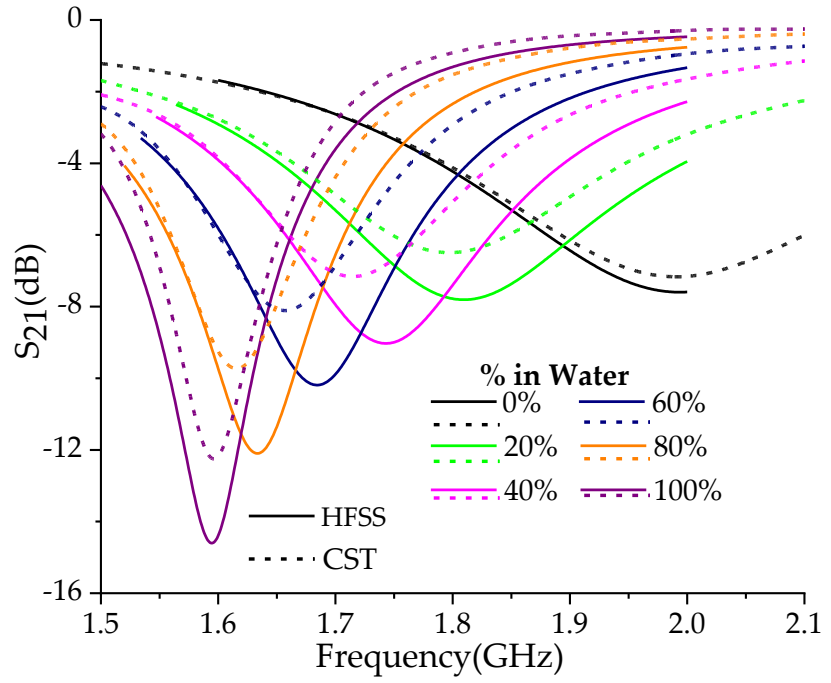

(a)

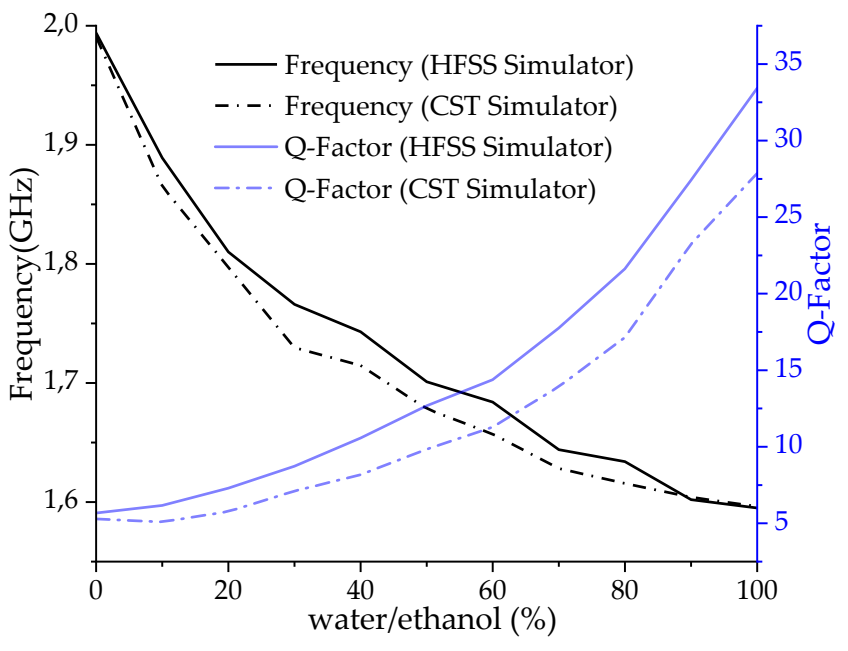

(b)

Figure 12. Simulated results: (a) $S_{21}$ response and (b) resonant frequency and $Q$ factor for different mixture water concentrations, with $\mathrm{r}=3.75 \mathrm{~mm}$.

In the same way, for $r=5 \mathrm{~mm}$ (Figure 13), the sensitivity was improved by more than 3 times relative to that of $r=0.75 \mathrm{~mm}$, with a decrease in the quality factor by $30 \%$. The $S_{21}$ HFSS validation results were close to those obtained by CST for different concentrations of water in the mixture. The resonant frequency reached values of around $1.4 \mathrm{GHz}$. 


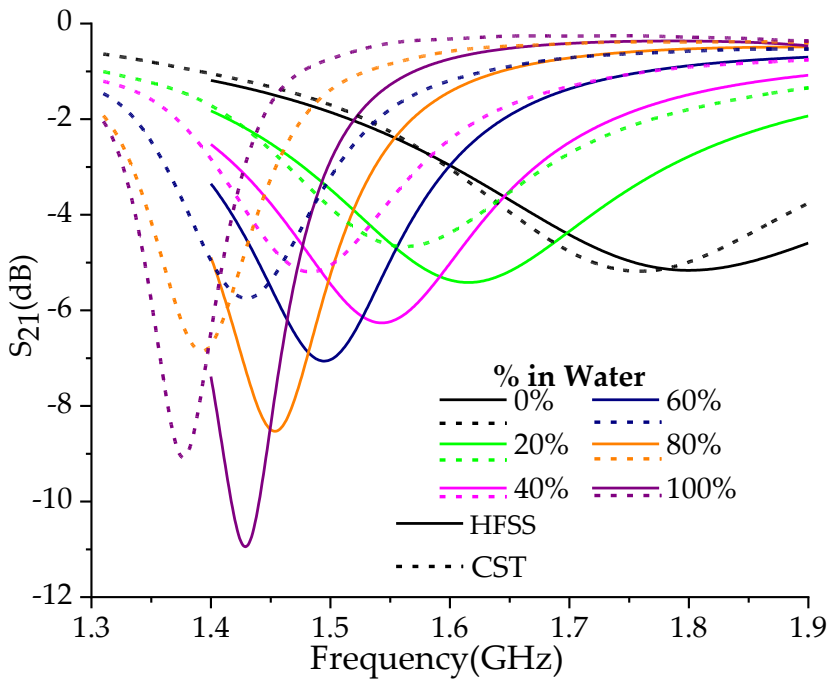

(a)

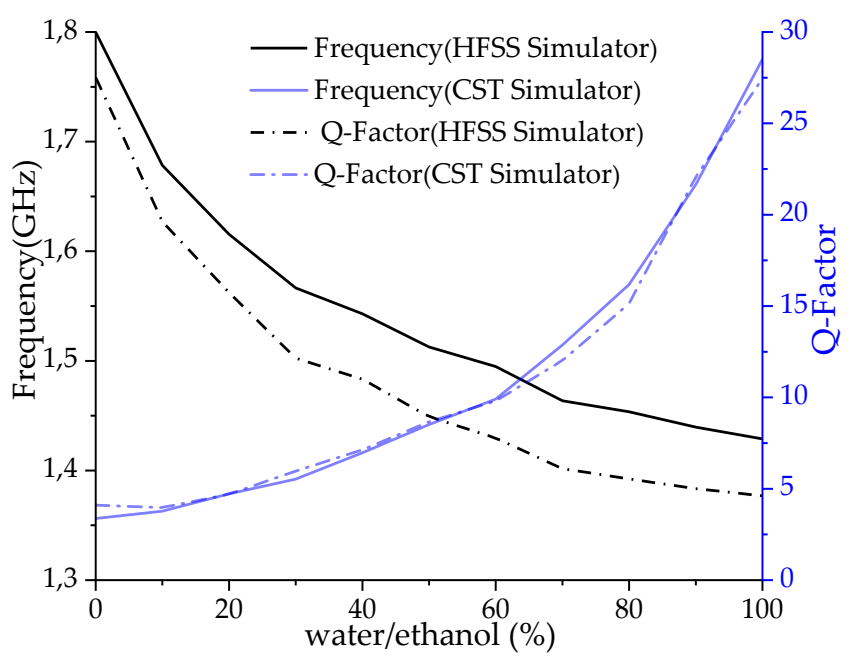

(b)

Figure 13. Simulated results: (a) $S_{21}$ response and (b) resonant frequency and $Q$ factor for different mixture water concentrations, with $\mathrm{r}=5 \mathrm{~mm}$.

According to Table 3, the accuracy and reliability of the proposed device was improved through five measurements for different tube radii. For instance, tubes with $\mathrm{r}=0.75$ and $1.5 \mathrm{~mm}$ had higher $\mathrm{Q}$ factors, and were mainly used to extract the imaginary part $\left(\varepsilon^{\prime \prime}\right)$. Tubes with larger radii $(r=3.75$ and $5 \mathrm{~mm})$ had a sensitivity range frequency of $400 \mathrm{MHz}$; hence, they were advantageously used for permittivity and the real part $\left(\varepsilon^{\prime}\right)$ extraction, since $\varepsilon^{\prime}$ and $\varepsilon^{\prime \prime}$ are directly related to $\Delta \mathrm{fr}$ and to $\mathrm{Q}$ factor, respectively [45].

Table 3. Sensitivity for different tube radius.

\begin{tabular}{ccccc}
\hline Tube Radius (mm) & $\begin{array}{c}\text { Resonant Frequency } \\
\mathbf{0 \%} \mathbf{( M H z )}\end{array}$ & $\begin{array}{c}\text { Resonant Frequency } \\
\mathbf{1 0 0} \mathbf{( M H z )}\end{array}$ & $\begin{array}{c}\Delta \text { fr } \\
\mathbf{( M H z )}\end{array}$ & $\begin{array}{c}\text { Maximum Q Factor } \\
\mathbf{( \% )}\end{array}$ \\
\hline 0.75 & 2403.7 & 2284.3 & 119.4 & 88.4 \\
1.5 & 2303.6 & 2047.8 & 255.8 & 53.2 \\
2.5 & 2061.1 & 1819.6 & 241.5 & 44.1 \\
3.75 & 1990.7 & 1596.3 & 394.5 & 27.9 \\
5 & 1758.6 & 1376.9 & 381.7 & 23.3 \\
\hline
\end{tabular}

\subsection{Complex Permittivity Extraction}

The least squares method [32] was used to determine the complex permittivity $\left(\varepsilon^{\prime} x+j \varepsilon^{\prime \prime} x\right)$ for different concentrations of ethanol in water. The complex permittivity functions are related to the change in the resonant frequency and the $Q$ factor. The change in the resonant frequency and the $\mathrm{Q}$ factor is described in terms of the complex permittivity of the liquid sample, using the linear equations [32,41] translated into matrix $\mathrm{M}$ (Equation (1)). For a mathematical analysis allowing the determination of the matrix coefficients, the reference values of the complex permittivity for different concentrations were extracted from [43]. These values are given in tables and illustrated by figures in Appendix A, so as to provide a better understanding of water-ethanol mixture concentrations for important frequency ranges.

$$
\left[\begin{array}{c}
\Delta f \\
\Delta Q
\end{array}\right]=\left[\begin{array}{ll}
m_{11} & m_{12} \\
m_{21} & m_{22}
\end{array}\right]\left[\begin{array}{c}
\Delta \varepsilon^{\prime} \\
\Delta \varepsilon^{\prime \prime}
\end{array}\right]
$$

where:

$$
\Delta f=\Delta f_{\text {sample }}-\Delta f_{\text {reference }}
$$




$$
\begin{gathered}
\Delta Q=\Delta Q_{\text {sample }}-\Delta Q_{\text {reference }} \\
\Delta \varepsilon=\Delta \varepsilon_{\text {sample }}-\Delta \varepsilon_{\text {reference }}
\end{gathered}
$$

where $m_{11}, m_{12}, m_{21}$, and $m_{22}$ are unknown coefficients, $\Delta \varepsilon$ is the complex permittivity, $\Delta f$ is the resonant frequency, and $\Delta Q$ is the $\mathrm{Q}$ factor. The reference value for analysis purposes is taken at $50 \%$ water concentration. The shifts in the values related to the variation in the complex permittivity, the resonant frequency, and the $\mathrm{Q}$ factor for different samples of the water-ethanol mixture are defined by the matrices $X, Y_{1}$, and $Y_{2}$, respectively, as follows:

$$
\begin{gathered}
{\left[\begin{array}{cc}
\Delta \varepsilon_{0 \%}^{\prime} & \Delta \varepsilon^{\prime \prime} \\
\Delta \varepsilon_{10 \%}^{\prime \prime} & \Delta \varepsilon_{10 \%}^{\prime \prime} \\
\Delta \varepsilon_{20 \%}^{\prime} & \Delta \varepsilon_{20 \%}^{\prime \prime} \\
\Delta \varepsilon_{30 \%}^{\prime} & \Delta \varepsilon_{30 \%}^{\prime \prime} \\
\Delta \varepsilon_{40 \%}^{\prime} & \Delta \varepsilon_{40 \%}^{\prime \prime} \\
\Delta \varepsilon_{50 \%}^{\prime} & \Delta \varepsilon_{50 \%}^{\prime \prime} \\
\Delta \varepsilon_{60 \%}^{\prime \prime} & \Delta \varepsilon_{60 \%}^{\prime \prime} \\
\Delta \varepsilon_{70 \%}^{\prime} & \Delta \varepsilon_{70 \%}^{\prime \prime} \\
\Delta \varepsilon_{80 \%}^{\prime} & \Delta \varepsilon_{80 \%}^{\prime \prime} \\
\Delta \varepsilon_{90 \%}^{\prime} & \Delta \varepsilon_{90 \%}^{\prime \prime} \\
\Delta \varepsilon_{100 \%}^{\prime} & \Delta \varepsilon_{100 \%}^{\prime \prime}
\end{array}\right]=\left[\begin{array}{cc}
-34.2259 & -5.2866 \\
-26.6591 & -1.9484 \\
-20.3808 & -0.651 \\
-12.1428 & 0.4194 \\
-7.7491 & -0.3072 \\
0 & 0 \\
5.5436 & -0.1577 \\
16.0126 & -0.526 \\
21.5426 & -2.4037 \\
28.4697 & -5.009 \\
33.4518 & -6.732
\end{array}\right], Y_{1}=\left[\begin{array}{c}
\Delta f_{0 \%} \\
\Delta f_{10 \%} \\
\Delta f_{20 \%} \\
\Delta f_{30 \%} \\
\Delta f_{40 \%} \\
\Delta f_{50 \%} \\
\Delta f_{60 \%} \\
\Delta f_{70 \%} \\
\Delta f_{80 \%} \\
\Delta f_{90 \%} \\
\Delta f_{100 \%}
\end{array}\right]=\left[\begin{array}{c}
0.3124 \\
0.1867 \\
0.1189 \\
0.0514 \\
0.0365 \\
0 \\
-0.0212 \\
-0.0501 \\
-0.0626 \\
-0.0742 \\
-0.082
\end{array}\right] \text { and }} \\
Y_{2}=\left[\begin{array}{c}
\Delta Q_{0 \%} \\
\Delta Q_{10 \%} \\
\Delta Q_{20 \%} \\
\Delta Q_{30 \%} \\
\Delta Q_{40 \%} \\
\Delta Q_{50 \%} \\
\Delta Q_{60 \%} \\
\Delta Q_{70 \%} \\
\Delta Q_{80 \%} \\
\Delta Q_{90 \%} \\
\Delta Q_{100 \%}
\end{array}\right]=\left[\begin{array}{c}
-4.5466 \\
-4.7513 \\
-4.0621 \\
-2.7325 \\
-1.6591 \\
0 \\
1.4484 \\
4.0915 \\
7.3011 \\
13.3947 \\
18.0188
\end{array}\right]
\end{gathered}
$$

After having obtained the complex permittivity, the resonant frequency, and the $\mathrm{Q}$ factor for the different samples of the water-ethanol mixtures, we had only to apply the initial matrix model given in (1). Thanks to a detailed algebraic analysis, Equations (5) and (6) were generated [32]. Thus, the unknown coefficients can be determined as given in (7):

$$
\begin{aligned}
& {\left[\begin{array}{ll}
m_{11} & m_{12}
\end{array}\right]^{T}=\left(X^{T} X\right)^{-1} \cdot X^{T} \cdot Y_{1}} \\
& {\left[\begin{array}{ll}
m_{11} & m_{12}
\end{array}\right]^{T}=\left(X^{T} X\right)^{-1} \cdot X^{T} \cdot Y_{1}}
\end{aligned}
$$

The final matrix providing data on the different water-ethanol samples is described by (8). These calculated coefficients are used to determine the complex permittivity of any given sample as a function of the change in the sample's resonant frequency and $Q$ factor:

$$
\begin{gathered}
{\left[\begin{array}{ll}
m_{11} & m_{12} \\
m_{21} & m_{22}
\end{array}\right]=\left[\begin{array}{cc}
-0.0057 & -0.0187 \\
0.2734 & -1.1230
\end{array}\right]} \\
{\left[\begin{array}{c}
\Delta \varepsilon^{\prime} \\
\Delta \varepsilon^{\prime \prime}
\end{array}\right]=\left[\begin{array}{ll}
m_{11} & m_{12} \\
m_{21} & m_{22}
\end{array}\right]^{-1}\left[\begin{array}{c}
\Delta f_{\text {res }} \\
\Delta Q
\end{array}\right]=\left[\begin{array}{ll}
-97.4829 & 1.6231 \\
-23.7329 & -0.4953
\end{array}\right]\left[\begin{array}{c}
\Delta f_{\text {res }} \\
\Delta Q
\end{array}\right]}
\end{gathered}
$$


Table 4 shows a comparison of the proposed sensing structures with the literature in terms of sensitivity and $Q$ factor.

Table 4. Comparison of the proposed sensor with data reported in the literature.

\begin{tabular}{|c|c|c|c|c|}
\hline Reference & $\begin{array}{c}\text { 0\% Water } \\
\text { Concentration } \\
\text { Resonant Frequency } \\
(\mathrm{MHz})\end{array}$ & $\begin{array}{c}100 \% \text { Water } \\
\text { Concentration } \\
\text { Resonant Frequency } \\
(\mathrm{MHz})\end{array}$ & $\Delta \mathrm{f}(\mathrm{MHz})$ & Maximum Q Factor \\
\hline [18] & 3980 & 4250 & 270 & 7 \\
\hline [20] & 1920 & 1530 & 390 & 9 \\
\hline [32] & 2370 & 2020 & 350 & 32 \\
\hline [34] & 1050 & 1500 & 450 & 5 \\
\hline [35] & 265 & 210 & 55 & 8 \\
\hline [37] & 1997 & 1962 & 35 & 42 \\
\hline [41] & 2348 & 2302 & 46 & 47 \\
\hline [46] & 1960 & 1855 & 105 & 26 \\
\hline$[47]$ & 3050 & 2990 & 60 & 55 \\
\hline Proposed flat structure & 2418.5 & 2330.4 & 88.1 & 72.71 \\
\hline Proposed bended structure & 1990.7 & 1596.3 & 394.5 & 27.9 \\
\hline
\end{tabular}

\section{Conclusions}

This paper proposes two small, low-cost, and highly sensitive microwave CSRR-based sensors for liquid characterization. The capillary glass test tube is filled with a waterethanol mixture placed parallel to the sensor's ground surface in order to determine the dielectric parameters of different mixture concentrations. The CSRR-based bended sensor was designed by folding the flat sensor around an arbitrary cylinder. Very important results were obtained. The originality of the bended sensor offers the possibility of changing the test tube quickly and easily for multiple measurements. The diversity of the sensor's bended shape and the modification of the radius of the test tube significantly improve the sensitivity at different resonant frequencies $(1.8 \mathrm{GHz}, 1.9 \mathrm{GHz}, 2 \mathrm{GHz}$, and $2.4 \mathrm{GHz})$. The proposed sensors have several advantages, such as small size, low cost, multi-performance ability, high sensitivity, and easy handling, making them ideal candidates for various applications.

Author Contributions: Conceptualization, S.M. (Said Mosbah), C.Z. and D.S.; methodology, S.M. (Said Mosbah), I.E. and M.P.; software, S.M. (Said Mosbah), M.L.B., S.M. (Samira Mekki) and R.Z.; validation, I.E., C.Z. and D.S.; formal analysis, S.M. (Samira Mekki); investigation, M.P. and J.R.; writing-original draft preparation, S.M. (Said Mosbah), C.Z. and D.S.; writing—review and editing, M.L.B., S.M. (Samira Mekki) and I.E.; visualization, S.M. (Said Mosbah); supervision, R.A.A.-A. and C.Z.; project administration, J.R. and I.E.; funding acquisition, J.R. and I.E. All authors have read and agreed to the published version of the manuscript.

Funding: This work was supported by the Moore4Medical project, funded within ECSEL JU in collaboration with the EU H2020 Framework Programme (H2020/2014-2020) under grant agreement H2020-ECSEL-2019-IA-876190, and the Fundação para a Ciência e Tecnologia (ECSEL/0006/2019). This project received funding in part from the DGRSDT (Direction Générale de la Recherche Scientifique et du Développement Technologique), MESRS (Ministry of Higher Education and Scientific Research), Algeria.

Data Availability Statement: All data are included within the manuscript.

Acknowledgments: This work was also supported by the General Directorate of Scientific Research and Technological Development (DGRSDT)-Ministry of Higher Education and Scientific Research (MESRS), Algeria, and funded by the FCT/MEC through national funds and, when applicable, co-financed by the ERDF, under the PT2020 Partnership Agreement under the UID/EEA/50008/2020 project.

Conflicts of Interest: The authors declare no conflict of interest. 


\section{Appendix A}

The properties of water-ethanol mixture concentration and complex permittivity are given in [44], and are represented in the following figures. The difficulty encountered when reading the data as described in [44] forced us to reproduce these data in Figure A1. Two tables describing the properties of the water-ethanol (real and imaginary parts of permittivity) mixture are given in Tables A1 and A2 from [44]. In this appendix, the work was based mainly on the work presented in [44], so as to provide the frequency dependence of the complex permittivity of any water concentration (Figure A1), which will serve as a basis for future research. In our case, the work is limited to the $1.5-3.5 \mathrm{GHz}$ frequency band for water-ethanol mixtures (Tables A1 and A2).

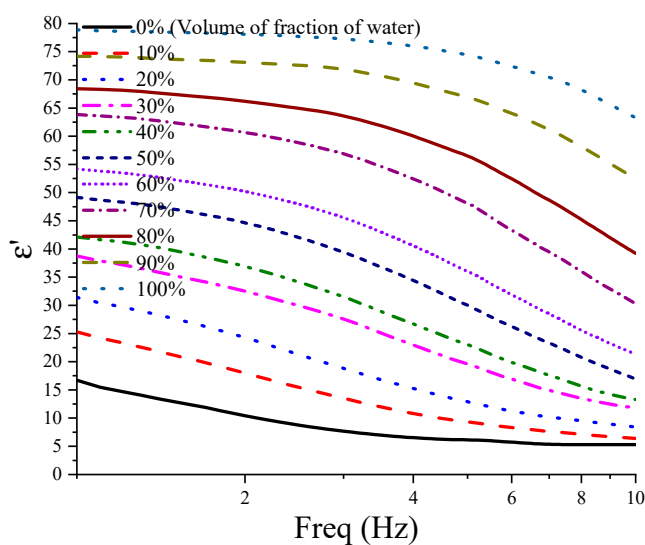

(a)

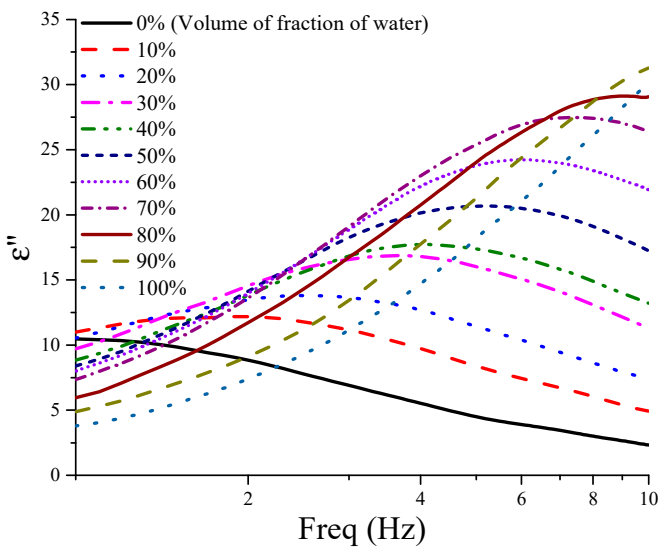

(b)

Figure A1. Frequency dependence of complex permittivity [44]: (a) real part; (b) imaginary part.

Table A1. Measured real dielectric spectra for water-ethanol mixture at $25{ }^{\circ} \mathrm{C}$ and different volume fractions; data reported from [44].

\begin{tabular}{cccccccccccc}
\hline $\mathbf{F}(\mathbf{G H z})$ & $\mathbf{0} \%$ & $\mathbf{1 0} \%$ & $\mathbf{2 0} \%$ & $\mathbf{3 0} \%$ & $\mathbf{4 0} \%$ & $\mathbf{5 0} \%$ & $\mathbf{6 0} \%$ & $\mathbf{7 0} \%$ & $\mathbf{8 0} \%$ & $\mathbf{9 0} \%$ & $\mathbf{1 0 0} \%$ \\
\hline 1.5 & 12.8519 & 21.0867 & 27.566 & 35.2247 & 39.6522 & 47.0192 & 52.2535 & 62.3769 & 67.3889 & 73.6248 & 78.4483 \\
1.6 & 12.335 & 20.433 & 26.882 & 34.657 & 39.067 & 46.536 & 51.830 & 62.009 & 67.136 & 73.52 & 78.379 \\
1.7 & 11.8721 & 19.8409 & 26.2388 & 34.1461 & 38.5128 & 46.0731 & 51.4296 & 61.6617 & 66.9092 & 73.4357 & 78.3121 \\
1.8 & 11.3234 & 19.179 & 25.5572 & 33.5753 & 37.9806 & 45.6131 & 51.0303 & 61.338 & 66.6868 & 73.3392 & 78.2389 \\
1.9 & 10.8541 & 18.5743 & 24.9102 & 33.0398 & 37.4472 & 45.1421 & 50.6211 & 61.0071 & 66.447 & 73.2332 & 78.1716 \\
2 & 10.4244 & 17.9912 & 24.2695 & 32.5075 & 36.9012 & 44.6503 & 50.1939 & 60.6629 & 66.1929 & 73.12 & 78.1021 \\
2.1 & 10.0188 & 17.4183 & 23.6274 & 31.9647 & 36.341 & 44.1386 & 49.7499 & 60.304 & 65.9307 & 73.0038 & 78.0283 \\
2.2 & 9.6427 & 16.8679 & 22.995 & 31.4244 & 35.7738 & 43.6112 & 49.2946 & 59.9344 & 65.6675 & 72.8897 & 77.9499 \\
2.3 & 9.304 & 16.3549 & 22.3861 & 30.9054 & 35.2085 & 43.0745 & 48.8339 & 59.5598 & 65.4111 & 72.7818 & 77.8677 \\
2.4 & 9.0006 & 15.8796 & 21.8051 & 30.4104 & 34.6493 & 42.5389 & 48.3722 & 59.1837 & 65.1676 & 72.6806 & 77.7838 \\
2.5 & 8.7265 & 15.4338 & 21.2502 & 29.9319 & 34.0992 & 42.0134 & 47.9121 & 58.808 & 64.9361 & 72.5828 & 77.7011 \\
2.6 & 8.4771 & 15.0114 & 20.7194 & 29.463 & 33.5615 & 41.4977 & 47.4517 & 58.4318 & 64.7056 & 72.4804 & 77.6186 \\
2.7 & 8.2487 & 14.6098 & 20.2112 & 28.9968 & 33.0362 & 40.9826 & 46.9851 & 58.0515 & 64.4607 & 72.3615 & 77.5328 \\
2.8 & 8.0394 & 14.228 & 19.725 & 28.5265 & 32.5193 & 40.4626 & 46.5099 & 57.6652 & 64.1927 & 72.2178 & 77.4422 \\
2.9 & 7.8489 & 13.8649 & 19.2613 & 28.049 & 32.0087 & 39.9424 & 46.0304 & 57.2748 & 63.903 & 72.0503 & 77.3496 \\
3 & 7.6754 & 13.518 & 18.819 & 27.5659 & 31.5029 & 39.4261 & 45.5487 & 56.879 & 63.5945 & 71.863 & 77.2556 \\
\hline
\end{tabular}


Table A2. Measured imaginary dielectric spectra for water-ethanol mixture at $25^{\circ} \mathrm{C}$ and different volume fractions; data reported from [44].

\begin{tabular}{cccccccccccc}
\hline F(GHz) & $\mathbf{0} \%$ & $\mathbf{1 0} \%$ & $\mathbf{2 0} \%$ & $\mathbf{3 0} \%$ & $\mathbf{4 0} \%$ & $\mathbf{5 0} \%$ & $\mathbf{6 0} \%$ & $\mathbf{7 0} \%$ & $\mathbf{8 0} \%$ & $\mathbf{9 0} \%$ & $\mathbf{1 0 0} \%$ \\
\hline 1.5 & 9.857 & 12.0791 & 12.4836 & 12.5329 & 11.5566 & 11.3342 & 11.0666 & 10.4624 & 8.8525 & 7.0544 & 5.5275 \\
1.6 & 9.639 & 12.0977 & 12.7086 & 12.9647 & 12.0202 & 11.9023 & 11.6584 & 11.1057 & 9.4186 & 7.4721 & 5.9109 \\
1.7 & 9.422 & 12.0869 & 12.8847 & 13.3445 & 12.4596 & 12.4676 & 12.2457 & 11.7436 & 10.0072 & 7.88 & 6.2745 \\
1.8 & 9.2413 & 12.1474 & 13.1168 & 13.7721 & 12.9276 & 13.0323 & 12.8336 & 12.3691 & 10.5878 & 8.2944 & 6.6377 \\
1.9 & 9.0486 & 12.1806 & 13.3146 & 14.1746 & 13.3837 & 13.5877 & 13.4095 & 12.9892 & 11.1687 & 8.7079 & 7.0145 \\
2 & 8.8445 & 12.1827 & 13.4801 & 14.5505 & 13.8239 & 14.1311 & 13.9734 & 13.6051 & 11.7274 & 9.1221 & 7.3991 \\
2.1 & 8.634 & 12.1507 & 13.611 & 14.8947 & 14.2411 & 14.6573 & 14.5224 & 14.2157 & 12.2563 & 9.5372 & 7.7857 \\
2.2 & 8.4198 & 12.0882 & 13.7056 & 15.2029 & 14.6299 & 15.1566 & 15.0538 & 14.818 & 12.7667 & 9.9527 & 8.1704 \\
2.3 & 8.2037 & 12.0029 & 13.7659 & 15.4741 & 14.9887 & 15.622 & 15.5695 & 15.4079 & 13.277 & 10.3688 & 8.5512 \\
2.4 & 7.9914 & 11.9011 & 13.7973 & 15.7088 & 15.3174 & 16.057 & 16.073 & 15.9822 & 13.7915 & 10.7868 & 8.9274 \\
2.5 & 7.7885 & 11.7873 & 13.8066 & 15.9089 & 15.6177 & 16.4708 & 16.5661 & 16.5393 & 14.3003 & 11.2093 & 9.2995 \\
2.6 & 7.5949 & 11.6664 & 13.8002 & 16.0801 & 15.8952 & 16.8688 & 17.0509 & 17.0811 & 14.7989 & 11.6399 & 9.6675 \\
2.7 & 7.408 & 11.5426 & 13.7823 & 16.2304 & 16.1568 & 17.2512 & 17.5308 & 17.6109 & 15.2939 & 12.0819 & 10.0337 \\
2.8 & 7.2292 & 11.4171 & 13.753 & 16.3635 & 16.4035 & 17.615 & 18.0042 & 18.1281 & 15.7885 & 12.5332 & 10.4033 \\
2.9 & 7.0617 & 11.289 & 13.7092 & 16.4789 & 16.6303 & 17.9543 & 18.4616 & 18.6269 & 16.2732 & 12.9858 & 10.78 \\
3 & 6.9029 & 11.1574 & 13.6504 & 16.5768 & 16.8335 & 18.2642 & 18.8947 & 19.1053 & 16.7367 & 13.4346 & 11.1603 \\
\hline
\end{tabular}

\section{References}

1. Gao, M.; Pan, J.-S.; Li, J.; Zhang, Z.; Chai, Q.-W. 3-D Terrains Deployment of Wireless Sensors Network by Utilizing Parallel Gases Brownian Motion Optimization. J. Internet Technol. 2021, 22, 13-29.

2. Zegadi, R.; Lorrain, N.; Bodiou, L.; Guendouz, M.; Ziet, L.; Charrier, J. Enhanced Mid-Infrared Gas Absorption Spectroscopic Detection Using Chalcogenide or Porous Germanium Waveguides. J. Opt. 2021, 23, 035102. [CrossRef]

3. Zegadi, R.; Ziet, L.; Zegadi, A. Design of High Sensitive Temperature Sensor Based on Two-Dimensional Photonic Crystal. Silicon 2020, 12, 2133-2139. [CrossRef]

4. Yuan, C.; Sun, X. Fingerprint Liveness Detection Adapted to Different Fingerprint Sensors Based on Multiscale Wavelet Transform and Rotation-Invarient Local Binary Pattern. J. Internet Technol. 2018, 19, 91-98.

5. Malekian, R.; Thakur, A.; Nair, L.; Pedersen, C.F. A Sensor Based Peer to Peer Vehicle Data Sharing System, an Internet of Vehicles Approach. J. Internet Technol. 2018, 19, 2155-2162.

6. Kim, K.T.; Youn, H.Y. A Dynamic Level-Based Routing Protocol for Energy Efficiency in Wireless Sensor Networks. J. Internet Technol. 2017, 18, 11-21.

7. Chudpooti, N.; Duangrit, N.; Sangpet, P.; Akkaraekthalin, P.; Imberg, B.U.; Robertson, I.D.; Somjit, N. In-Situ Self-Aligned NaClSolution Fluidic-Integrated Microwave Sensors for Industrial and Biomedical Applications. IEEE Access 2020, 8, 188897-188907. [CrossRef]

8. Entesari, K.; Helmy, A.A.; Moslehi-Bajestan, M. Integrated Systems for Biomedical Applications: Silicon-Based RF $\backslash /$ Microwave Dielectric Spectroscopy and Sensing. IEEE Microw. Mag. 2017, 18, 57-72. [CrossRef]

9. Vlachogiannakis, G.; Hu, Z.; Shivamurthy, H.T.; Neto, A.; Pertijs, M.A.P.; de Vreede, L.C.N.; Spirito, M. Miniaturized Broadband Microwave Permittivity Sensing for Biomedical Applications. IEEE J. Electromagn. RF Microw. Med. Biol. 2019, 3, 48-55. [CrossRef]

10. Bourqui, J.; Fear, E.C. Shielded UWB Sensor for Biomedical Applications. IEEE Antennas Wirel. Propag. Lett. 2012, 11, 1614-1617. [CrossRef]

11. Helmy, A.A.; Jeon, H.-J.; Lo, Y.-C.; Larsson, A.J.; Kulkarni, R.; Kim, J.; Silva-Martinez, J.; Entesari, K. A Self-Sustained CMOS Microwave Chemical Sensor Using a Frequency Synthesizer. IEEE J. Solid State Circuits 2012, 47, 2467-2483. [CrossRef]

12. Mirzaei, A.; Neri, G. Microwave-Assisted Synthesis of Metal Oxide Nanostructures for Gas Sensing Application: A Review. Sens. Actuators B Chem. 2016, 237, 749-775. [CrossRef]

13. Zarifi, M.H.; Deif, S.; Abdolrazzaghi, M.; Chen, B.; Ramsawak, D.; Amyotte, M.; Vahabisani, N.; Hashisho, Z.; Chen, W.; Daneshmand, M. A Microwave Ring Resonator Sensor for Early Detection of Breaches in Pipeline Coatings. IEEE Trans. Ind. Electron. 2018, 65, 1626-1635. [CrossRef]

14. Jilani, M.T.; Rehman, M.Z.U.; Khan, A.M.; Chughtai, O.; Abbas, M.A.; Khan, M.T. An Implementation of IoT-Based Microwave Sensing System for the Evaluation of Tissues Moisture. Microelectron. J. 2019, 88, 117-127. [CrossRef]

15. Bakır, M.; Karaaslan, M.; Unal, E.; Akgol, O.; Sabah, C. Microwave Metamaterial Absorber for Sensing Applications. Opto Electron. Rev. 2017, 25, 318-325. [CrossRef]

16. Kurmendra; Kumar, R. A Review on RF Micro-Electro-Mechanical-Systems (MEMS) Switch for Radio Frequency Applications. Microsyst. Technol. 2021, 27, 2525-2542. [CrossRef]

17. Zhang, K.; Bariani, F.; Dong, Y.; Zhang, W.; Meystre, P. Proposal for an Optomechanical Microwave Sensor at the Subphoton Level. Phys. Rev. Lett. 2015, 114, 113601. [CrossRef] 
18. Rawat, V.; Dhobale, S.; Kale, S.N. Ultra-Fast Selective Sensing of Ethanol and Petrol Using Microwave-Range Metamaterial Complementary Split-Ring Resonators. J. Appl. Phys. 2014, 116, 164106. [CrossRef]

19. Petrin, A. Wave Propagation; IntechOpen: London, UK, 2011; ISBN 978-953-307-275-3.

20. Ebrahimi, A.; Withayachumnankul, W.; Al-Sarawi, S.; Abbott, D. High-Sensitivity Metamaterial-Inspired Sensor for Microfluidic Dielectric Characterization. IEEE Sens. J. 2014, 14, 1345-1351. [CrossRef]

21. Veselago, V.G. The electrodynamics of substances with simultaneously negative values of $\varepsilon$ and $\mu$. Sov. Phys. Usp. 1968, 10, 509-514. [CrossRef]

22. Sarkhel, A.; Mitra, D.; Chaudhuri, S.R.B. A Compact Metamaterial with Multi-Band Negative-Index Characteristics. Appl. Phys. A 2016, 122, 471. [CrossRef]

23. Alqadami, A.S.M.; Jamlos, M.F.; Soh, P.J.; Rahim, S.K.A.; Vandenbosch, G.A.E.; Narbudowicz, A. Miniaturized Dual-Band Antenna Array with Double-Negative (DNG) Metamaterial for Wireless Applications. Appl. Phys. A 2016, 123, 22. [CrossRef]

24. Webb, B.A.; Ziolkowski, R.W. Metamaterial-Inspired Multilayered Structures Optimized to Enable Wireless Communications through a Plasmasonic Region. Appl. Phys. Lett. 2021, 118, 094102. [CrossRef]

25. Manage, P.S.; Naik, U.; Nargundkar, S.; Rayar, V. A Survey on Applications of Metamaterials in Antenna Design. In Proceedings of the 2020 Third International Conference on Smart Systems and Inventive Technology (ICSSIT), Tirunelveli, India, 20-22 August 2020; pp. 153-158.

26. Canet-Ferrer, J. Metamaterials and Metasurfaces; IntechOpen: London, UK, 2019; ISBN 978-1-78984-842-7.

27. Kayal, S.; Shaw, T.; Mitra, D. Design of Metamaterial-Based Compact and Highly Sensitive Microwave Liquid Sensor. Appl. Phys. A 2019, 126, 13. [CrossRef]

28. Muhammed, S.K.T.; Ansari, M.A.H.; Jha, A.K.; Akhtar, M.J. Design of SRR-Based Microwave Sensor for Characterization of Magnetodielectric Substrates. IEEE Microw. Wirel. Compon. Lett. 2017, 27, 524-526. [CrossRef]

29. Kiani, S.; Rezaei, P.; Navaei, M. Dual-Sensing and Dual-Frequency Microwave SRR Sensor for Liquid Samples Permittivity Detection. Measurement 2020, 160, 107805. [CrossRef]

30. Viswanathan, A.P.; Moolat, R.; Mani, M.; Va, S.; Pezholil, M. A Simple Electrically Small Microwave Sensor Based on Complementary Asymmetric Single Split Resonator for Dielectric Characterization of Solids and Liquids. Int. J. RF Microw. Comput. Aided Eng. 2020, 30, e22462. [CrossRef]

31. Vélez, P.; Su, L.; Grenier, K.; Mata-Contreras, J.; Dubuc, D.; Martín, F. Microwave Microfluidic Sensor Based on a Microstrip Splitter/Combiner Configuration and Split Ring Resonators (SRRs) for Dielectric Characterization of Liquids. IEEE Sens. J. 2017, 17, 6589-6598. [CrossRef]

32. Javed, A.; Arif, A.; Zubair, M.; Mehmood, M.Q.; Riaz, K. A Low-Cost Multiple Complementary Split-Ring Resonator-Based Microwave Sensor for Contactless Dielectric Characterization of Liquids. IEEE Sens. J. 2020, 20, 11326-11334. [CrossRef]

33. Zhao, W.-S.; Gan, H.-Y.; He, L.; Liu, Q.; Wang, D.-W.; Xu, K.; Chen, S.; Dong, L.; Wang, G. Microwave Planar Sensors for Fully Characterizing Magneto-Dielectric Materials. IEEE Access 2020, 8, 41985-41999. [CrossRef]

34. Gan, H.-Y.; Zhao, W.-S.; Liu, Q.; Wang, D.-W.; Dong, L.; Wang, G.; Yin, W.-Y. Differential Microwave Microfluidic Sensor Based on Microstrip Complementary Split-Ring Resonator (MCSRR) Structure. IEEE Sens. J. 2020, 20, 5876-5884. [CrossRef]

35. Lee, C.-S.; Bai, B.; Song, Q.-R.; Wang, Z.-Q.; Li, G.-F. Open Complementary Split-Ring Resonator Sensor for Dropping-Based Liquid Dielectric Characterization. IEEE Sens. J. 2019, 19, 11880-11890. [CrossRef]

36. Armghan, A.; Alanazi, T.M.; Altaf, A.; Haq, T. Characterization of Dielectric Substrates Using Dual Band Microwave Sensor. IEEE Access 2021, 9, 62779-62787. [CrossRef]

37. Kumar, A.; Rajawat, M.S.; Mahto, S.K.; Sinha, R. Metamaterial-Inspired Complementary Split Ring Resonator Sensor and Second-Order Approximation for Dielectric Characterization of Fluid. J. Electron. Mater. 2021, 50, 5925-5932. [CrossRef]

38. Zarifi, M.H.; Thundat, T.; Daneshmand, M. High Resolution Microwave Microstrip Resonator for Sensing Applications. Sens. Actuators A Phys. 2015, 233, 224-230. [CrossRef]

39. Haq, T.; Ruan, C.; Ullah, S.; Kosar, A. Reconfigurable Ultra Wide Band Notch Filter Based on Complementary Metamaterial. In Proceedings of the 2018 IEEE Asia-Pacific Conference on Antennas and Propagation (APCAP), Auckland, New Zealand, 5-8 August 2018; pp. 381-382.

40. Haq, T.; Ruan, C.; Zhang, X.; Ullah, S. Complementary Metamaterial Sensor for Nondestructive Evaluation of Dielectric Substrates. Sensors 2019, 19, 2100. [CrossRef] [PubMed]

41. Chuma, E.L.; Iano, Y.; Fontgalland, G.; Bravo Roger, L.L. Microwave Sensor for Liquid Dielectric Characterization Based on Metamaterial Complementary Split Ring Resonator. IEEE Sens. J. 2018, 18, 9978-9983. [CrossRef]

42. Yeo, J.; Lee, J.-I. High-Sensitivity Microwave Sensor Based on an Interdigital-Capacitor-Shaped Defected Ground Structure for Permittivity Characterization. Sensors 2019, 19, 498. [CrossRef] [PubMed]

43. Salim, A.; Lim, S. Complementary Split-Ring Resonator-Loaded Microfluidic Ethanol Chemical Sensor. Sensors 2016, 16, 1802. [CrossRef]

44. Bao, J.; Swicord, M.L.; Davis, C.C. Microwave Dielectric Characterization of Binary Mixtures of Water, Methanol, and Ethanol. J. Chem. Phys. 1996, 104, 4441-4450. [CrossRef]

45. Li, D.; Free, C.E.; Pitt, K.E.G.; Barnwell, P.G. A Simple Method for Accurate Loss Tangent Measurement of Dielectrics Using a Microwave Resonant Cavity. IEEE Microw. Wirel. Compon. Lett. 2001, 11, 118-120. [CrossRef] 
46. Withayachumnankul, W.; Jaruwongrungsee, K.; Tuantranont, A.; Fumeaux, C.; Abbott, D. Metamaterial-Based Microfluidic Sensor for Dielectric Characterization. Sens. Actuators A Phys. 2013, 189, 233-237. [CrossRef]

47. Awang, R.A.; Tovar-Lopez, F.J.; Baum, T.; Sriram, S.; Rowe, W.S.T. Meta-Atom Microfluidic Sensor for Measurement of Dielectric Properties of Liquids. J. Appl. Phys. 2017, 121, 094506. [CrossRef] 